\title{
Perancangan Sistem Informasi Laboratorium (SILAB) Terintegrasi Di Laboratorium Pelatihan Komputer STKIP PGRI Sumatera Barat
}

\author{
Ade Pratama \\ ${ }^{1}$ Dosen Pendidikan Informatika STKIP PGRI Sumbar \\ Adepratama984@gmail.com
}

\begin{abstract}
ABSTRAK
Laboratorium merupakan sarana dan tempat untuk mendukung proses pembelajaran yang didalamnya terkait dengan pengembangan pemahaman, keterampilan dan inovasi bidang ilmu pengetahuan. Berbagai aktivitas dilaksanakan di Labor seperti kegiatan praktikum dan administrasi Laboratorium Pelatihan Komputer masih dilakukan secara manual yaitu menggunakan komputer tetapi tidak berbasis pada sistem informasi. Penjadwalan, cetak absensi, pendataan peserta praktikum serta rekap vakasi praktikum masih menggunakan word dan excel. Sehingga seringkali mengalami kesulitan dalam menjadwalkan, merekap data mahasiswa, pencatatan absensi kegiatan praktikum bahkan rekap vakasi mengajar. Hal ini karena tidak terintegrasinya aktivitas praktikum kedalam sebuah sistem. Berdasarkan latar belakang diatas, maka pada makalah ini penulisan akan memamaparkan tahapan dalam pengembangan sebuah sistem informasi laboratorium yang dapat mengintegrasikan aktivitas praktikum, sehingga dapat mempermudah dalam proses penjadwalan, pendataan peserta praktikum, penilaian, dan rekap vakasi mengajar di Laboratorium Pelatihan Komputer
\end{abstract}

Kata Kunci :Perancangan Sistem Informasi

\section{PENDAHULUAN}

Laboratorium merupakan sarana dan tempat untuk mendukung proses pembelajaran yang didalamnya terkait dengan pengembangan pemahaman, keterampilan dan inovasi bidang ilmu pengetahuan. Berbagai aktivitas dilaksanakan di Labor seperti kegiatan praktikum dan administrasi Laboratorium Pelatihan Komputer masih dilakukan secara manual yaitu menggunakan komputer tetapi tidak berbasis pada sistem informasi. Penjadwalan, cetak absensi, pendataan peserta praktikum serta rekap vakasi praktikum masih menggunakan word dan excel. Sehingga seringkali mengalami kesulitan dalam menjadwalkan, merekap data mahasiswa, pencatatan absensi kegiatan praktikum bahkan rekap vakasi mengajar. Hal ini karena tidak terintegrasinya aktivitas praktikum kedalam sebuah sistem.

Berdasarkan latar belakang diatas, maka pada makalah ini penulisan akan memamaparkan tahapan dalam pengembangan sebuah sistem informasi laboratorium yang dapat mengintegrasikan aktivitas praktikum, sehingga dapat mempermudah dalam proses penjadwalan, pendataan peserta praktikum , penilaian, dan rekap vakasi mengajar di Laboratorium Pelatihan Komputer 


\section{Jurnal Edik Informatika}

ISSN : 2407-0491

E-ISSN : 2541-3716

Penelitian Bidang Komputer Sains dan Pendidikan Informatika

V2.i1(10-15)

\section{IDENTIFIKASI MASALAH}

Berdasarkan latar belakang masalah diatas, maka dapat diidentifikasi bahwa pembagian gelombang, absensi praktikum mahasiswa dan absensi instruktur / dosen laboratorium sampai pembayaran honor instruktur labor secara konvensional ini kurang efektif dan efisien disebabkan oleh beberapa faktor antara lain :

a. Dalam pelaksanaan absensi dan perekapan absensi menyita cukup banyak waktu dan tenaga

b. Pembagian gelombang praktikum masih kurang efektif dan efisien

c. Hasil absen harus ditulis dan perlu adanya perekapan absensi

d. Masih adanya peserta praktikum yang belum melakukan registrasi tetapi masih bisa mengikuti praktikum

\subsection{Batasan Masalah}

Adapun batasan masalah dalam penelitian ini adalah :

1. Aplikasi yang akan dibuat yaitu mencakup :
a. Registrasi Praktikum Mahasiswa Labor
b. Pembagian gelombang praktikum mahasiswa labor
c. Jadwal praktikum
d. Pembuatan absensi praktikum mahasiswa labor
e. Absensi instruktur labor
f. Presensi kehadiran
g. Nilai praktikum

2. Aplikasi yang dibangun yaitu berbasis web dan menggunakan bahasa pemrograman PHP, MysQ1

\section{ANALISIS DAN PERANCANGAN SISTEM}

a. Analisis Merupakan proses pengumpulan kebutuhan piranti lunak. Untuk memahami dasar dari program yang akan dibuat, seorang analisis harus mengetahui ruang lingkup informasi, fungsi-fungsi yang dibutuhkan, kemampuan kinerja yang ingin dihasilkan dan perancangan antarmuka pemakai piranti lunak tersebut. Pada tahap ini, dianalisis kebutuhan input, proses dan output dari Sistem Informasi Laboratorium.

b. Desain Perancangan piranti lunak Merupakan proses bertahap yang memfokuskan pada empat bagian penting, yaitu: Struktur data, arsitektur piranti lunak, detil prosedur, dan karakteristik antar muka pemakai. Pada tahap ini dilakukan CDM (Conseptual Data Model) , DataFlow Diagram (DFD), Rancangan Antar Muka pengguna dari Sistem Informasi Laboratorium.

c.Koding Pengkodean piranti lunak merupakan proses penulisan bahasa program agar piranti lunak tersebut dapat dijalankan oleh mesin. Pada tahapan ini, mulai mengimplementasikan desain sistem informasi laboratorium ke koding PHP dan penerapan aplikasi CRUD (Create, Retrieve, Update, Delete).

d.Pengujian Proses ini akan menguji kode program yang telah dibuat dengan memfokuskan pada bagian dalam piranti lunak. Proses pengujian sistem informasi laboratorium dengan menjalankan sistem, apakah fungsi-fungsi yang telah dibuat dapat berjalan dengan baik. Selain itu, pengujian sistem ini dilakukan dengan melibatkan mahasiswa sebagai percontohan dalam penggunaan sistem informasi.

e. Pemeliharaan Tahapan ini dilakukan setelah sistem informasi laboratorium telah diterapkan dan digunakan oleh mahasiswa, dosen dan bagian administrasi. Proses pemeliharaan sistem informasi laboratorium juga bertujuan mengembangkan silab, jika ada kebutuhan - kebutuhan yang belum diakomodir didalam sistem. 


\section{Jurnal Edik Informatika}

ISSN : 2407-0491

E-ISSN : 2541-3716

Penelitian Bidang Komputer Sains dan Pendidikan Informatika

V2.i1(10-15)

\subsection{PROSES ANALISIS SISTEM INFORMASI}

Rekayasa perangkat lunak yang digunakan pada perancangan sistem ini adalah ModifiedWaterfallMethod atau metode modifikasi air terjun. alur modified waterfall terbagi menjadi 5 tahapan, yaitu:

\section{Analisis Kebutuhan}

Pada tahap ini dilakukan analisis untuk keperluan dari sistem tersebut. Analisis ini dapat dilakukan dengan melakukan metode studyliteratur, wawancara langsung, ataupun dengan menggunakan quisioner pertanyaan.

2. Desain Sistem

Kemudian tahap selanjutnya adalah melakukan pendesainan sistem yang akan dibuat. Desain sistem yang dibuat mencakup:

\section{a. ERD (Entity Relation Diagram)}

Adalah suatu diagram perancangan sistem yang menyatakan relasi yang terdapat pada basis data sistem tersebut. ERD hanya mencakup tabel database yang ada pada sistem.

b. CD (ContextDiagram) Adalah suatu diagram perancangan sistem yang menyatakan alur kerja sistem tersebut secara menyeluruh beserta entitas yang bekerja didalamnya.

c. DFD (Data Flow Diagram)

Adalah suatu diagram pengembangan dari CD di mana pada diagram ini menjelaskan alur kerja suatu sistem sesuai dengan entitasnya masingmasing. Perbedaannya dibandingkan CD adalah DFD lebih menjelaskan alur kerja sistem secara terperinci dibandingkan CD.

3. Penulisan Kode Program (Implementasi)

4. Setelah itu dilakukan penulisan kode program sesuai dengan hasil analisa dan pendesainan yang telah dilakukan sebelumnya. Penulisan kode program bisa menggunakan perangkat lunak pendukung seperti Notepad++, DreamWeaver, Sublime Text, Lobster, Netbeans, Eclipse, dan lainlain.

5. Pengujian Program

Kemudian dilakukan pengujian sistem apakah sesuai dengan yang dibutuhkan atau tidak.

6. Pemeliharaan

Dan terakhir dilakukan pemeliharaan system agar sistem yang dibuat dapat dikelola lebih baik.

\section{PERANCANGAN INFORMASI (SILAB)}

\section{SISTEM}

LABORATORIUM

Bentuk rancangan tersebutdapat berupa Contex Diagram, dan CDM (Conseptual Data Model)

\section{a. Context Diagram}

Context Diagram digunakan untuk menggambarkan sistem informasi laboratorium dari sudut pandang pengguna. Context Diagram Silab dapat dilihat pada gambar 2

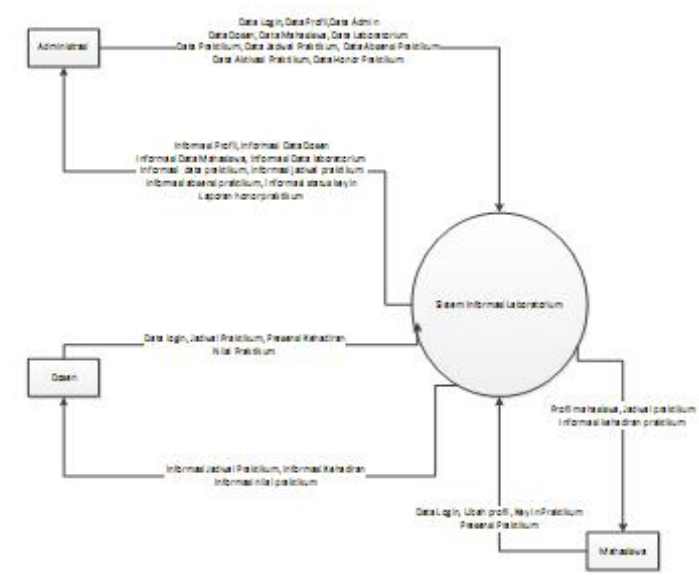

Gambar 1. Contex Diagram

Pada Context diagram terdapat 3 entitas eksternal antara lain administasi, dosen dan mahasiswa. Entitas Administasi memiliki aliran data ke sistem antara lain 
Data Login, Data Profil, Data Admin, Data Dosen, Data Mahasiswa, Data Laboratorium, Data Praktikum, Data Jadwal Praktikum, Data Absensi Praktikum, Data Aktivasi Praktikum, Data Honor Praktikum. Entitas Mahasiswa memiliki aliran data ke sistem yaitu Data Login, Ubah profil, Key In Praktikum, Presensi Praktikum. Sedangkan entitas Dosen memiliki aliran data ke SiLab yaitu Data login, Jadwal Praktikum, Presensi Kehadiran, Nilai Praktikum.

\section{b. CDM (Conseptual Data Model)} Conceptual data model (CDM) mengambarkan hubungan antar entitias yang saling berelasi antara satu dengan yang lain. Gambar CDM Silab dapat dilihat pada gambar 3 .

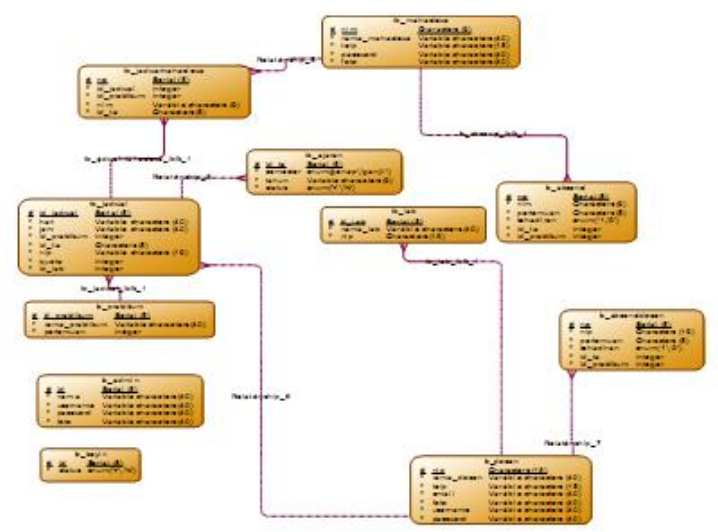

Gambar 2. CDM

\section{HASIL DAN IMPLEMENTASI}

Setelah dilakukan tahapan analis dan perancangan sistem, maka dihasilkan Sistem Informasi Laboratorium. Tampilan awal dari silab adalah halaman login seperti terlihat pada gambar 4

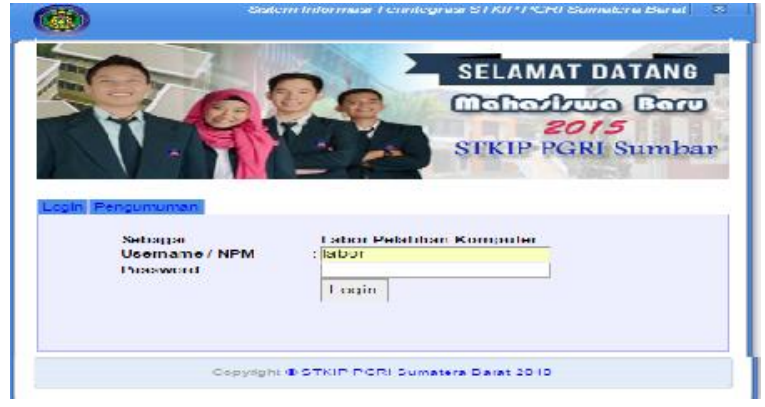

Gambar 3. Tampilan login dari SILAB

Terdapat 3 inputan yaitu login (nama login pengguna), password dan level dari user yang login. Pengguna dapat memilih ingin melakukan login ke SiLab menggunakan user sesuai dengan level usernya.

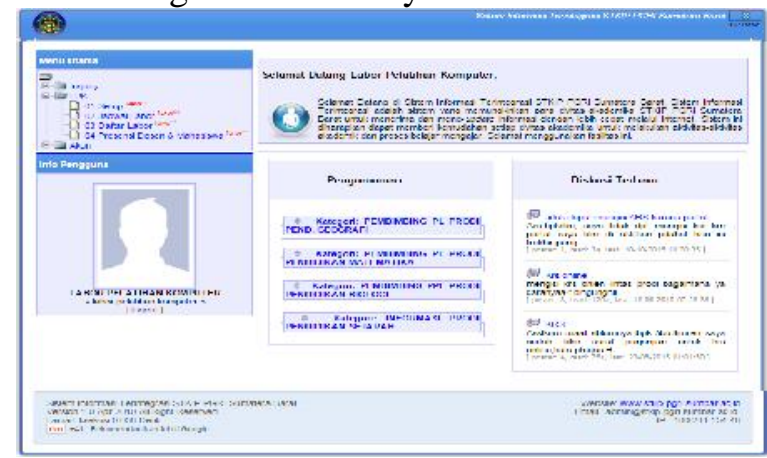

Gambar 4. Halaman Utama Administrasi

Gambar 5 merupakan tampilan halaman utama administrasi, halaman ini akan tampil jika user melalukan login dengan level sebagai administrasi. Pada halaman administrasi terdapat beberapa menu antara lain menu profil administasi, menu data admin, menu data, menu data dosen/asisten, menu data mahasiswa, menu data laboratorium, menu data praktikum, menu data jadwal praktikum, menu absensi praktikum dan menu data nilai 


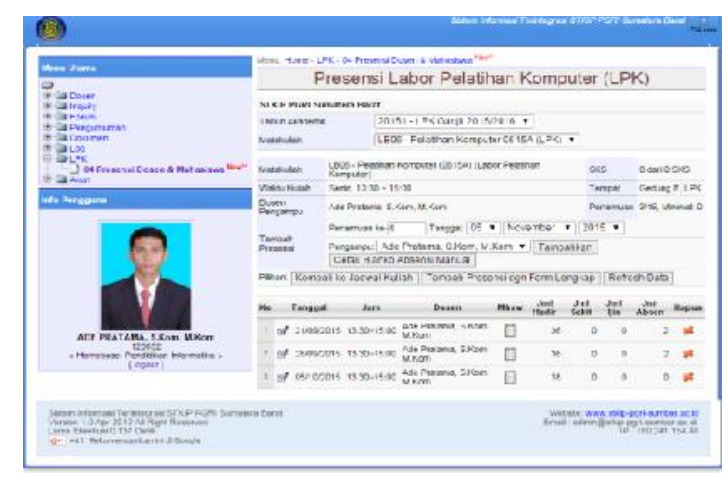

Gambar 5. Halaman Utama Dosen

Gambar 6 merupakan tampilan awal halaman utama dosen /instruktur, halaman ini akan tampil jika pengguna memilih login sebagai dosen. Pada halaman dosen terdapat beberapa menu antara lain

a. Menu Profil, menu ini menampilkan profil dosen yang sedang login dan dihalaman menu profil, dosen dapat melakukan proses pengubahan data profil.

b. Menu Key In Praktikum, menu ini dapat digunakan oleh dosen untuk melakukan key in praktikum berdasarkan matakuliah yang akan diampu

c. Menu Jadwal praktikum, digunakan oleh dosen untuk melihat jadwal praktikum yang diambil berdasarkan tahun akademik.

d. Menu presensi, digunakan oleh dosen untuk melakukan presensi kegiatan praktikum berdasarkan mata praktikum yang sedang diampu.

e. Menu Kehadiran, menu ini dapat digunakan untuk melihat rekap kehadiran mahasiswa dalam kegiatan praktikum berdasarkan matakuliah yang diampu.

f. Menu Nilai, disini dosen dapat mengentri nilai untuk masing-masing mata praktikum yang pernah dan sedang diampu.

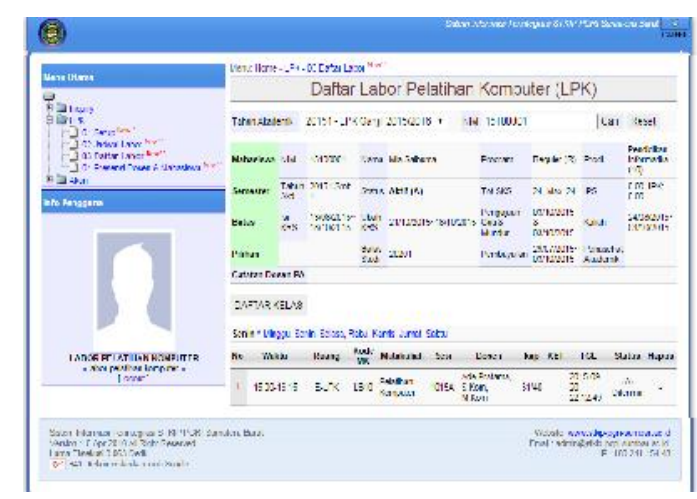

\section{Gambar 6 Halaman Utama Mahasiswa}

Gambar 6, merupakan tampilan awal halaman utama mahasiswa, halaman ini akan tampil jika pengguna memilih login sebagai mahasiswa. Pada halaman mahasiswa terdapat beberapa menu antara lain

a. Menu Profil, menu ini menampilkan profil mahasiswa yang sedang login dan dihalaman menu profil, mahasiswa dapat melakukan proses pengubahan data profil.

b. Menu Key In Praktikum, menu ini dapat digunakan oleh dosen untuk melakukan key in praktikum berdasarkan matakuliah yang akan diambil

c. Menu Jadwal praktikum, digunakan oleh mahasiswa untuk melihat jadwal praktikum yang diambil berdasarkan tahun akademik.

d. Menu presensi, digunakan oleh mahasiswa untuk melihat presensi kegiatan praktikum berdasarkan mata praktikum yang sedang diambil.

e. Menu Nilai, disini mahasiswa dapat melihat nilai praktikum yang pernah dan sedang diambil.

\section{KESIMPULAN DAN SARAN}

\subsection{Kesimpulan}

Setelah dilakukan tahapan merancang dan membangun sistem informasi berbasis web maka didapatkan kesimpulan sebagai beriku: 
ISSN : 2407-0491

Jurnal Edik Informatika

E-ISSN : 2541-3716

Penelitian Bidang Komputer Sains dan Pendidikan Informatika V2.i1(10-15)

1.Sistem informasi Laboratorium pelatihan komputer memiliki 3 Level pengguna yaitu

a.Mahasiswa,

b.Dosen/Asisten

c.Administrasi

2.SiLab telah diimplementasikan di Laboratorium pelatihan komputer, dan dapat membantu dalam pengelolaan kegiatan praktikum di Labor

\subsection{Saran}

Sebagai saran, sistem ini kedepannya dapat diitegrasikan dengan sistem informasi akademik yang dimiliki oleh STKIP PGRI Sumatera Barat

\section{DAFTAR PUSTAKA}

http://id.wikipedia.org/wiki/MySQL diakses pada 23 April 2013. Pukul 20.00 Wib

Jogiyanto HM.,2005. Analisis \& Disain Sistem Informasi .Penerbit Andi, Yogyakarta

Pressman, Roger.S. 1997. Software Engineering : A Practioner's Approach. 4th . McGrawHill. 